\title{
Association between helminth infections and diabetes mellitus in adults from the Lao People's Democratic Republic: a cross- sectional study
}

Nan Shwe Nwe Htun ${ }^{1,2}$, Peter Odermatt ${ }^{1,2}$, Phimpha Paboriboune ${ }^{3}$, Somphou Sayasone ${ }^{1,4}$, Malisa Vongsakid ${ }^{3}$, Vilayouth Phimolsarn-Nusith ${ }^{3}$, Xuan Duong Tran ${ }^{3}$, Phoum-Savath Ounnavong ${ }^{3}$, Navalone Andriama-Hefasoa ${ }^{3}$, Nilun-Done Senvanpan ${ }^{3}$, Anousine Homsana ${ }^{3}$, Baocher Lianosay ${ }^{3}$, Dalouny Xayavong ${ }^{3}$, Dimbitsoa Rakotomalala Robinson ${ }^{3}$, Phaivanh Bounsavath ${ }^{3}$, Phoy-Phaylinh Prasayasith ${ }^{3}$, Seng-Davanh Syphan ${ }^{3}$, Yi-Xiao Lư ${ }^{3}$, Kanchana Thilakoun ${ }^{3}$, Xaipa-Song Xaiyaphet ${ }^{3}$, Phout-Tasin Vongngakesone ${ }^{3}$, Ikenna C Eze $\mathrm{E}^{1,2}$, Medea Imboden ${ }^{1,2}$, Banchob Sripa ${ }^{5}$, Daniel Reinharz ${ }^{6}$ and Nicole Probst-Hensch ${ }^{1,2^{*}}$

\footnotetext{
Abstract

Background: As a result of epidemiological transition, the health systems of low- and middle-income countries are increasingly faced with a dual disease burden of infectious diseases and emerging non-communicable diseases. Little is known about the mutual influence of these two disease groups. The aim of this study was to investigate the cooccurrence of helminth infections and diabetes mellitus in adults in Lao People's Democratic Republic (Lao PDR).

Methods: We conducted a cross-sectional study among 1600 randomly selected adults aged 35 and older from four different socio-economical and ecological provinces. Information on socio-demographics, risk factors and health conditions was obtained from personal interviews. Clinical assessments including anthropometry (height, weight, waist and hip circumference) and blood pressure measurements were also conducted. Diabetes was classified based on selfreported diagnoses and a point-of-care glycated haemoglobin (HbA1c) test from finger prick blood samples. Stool samples for helminth diagnosis were examined with formalin-ether concentration technique for intestinal parasitic infections. The independent associations of helminth infections with diabetic status and $\mathrm{HbA1c}$ were assessed using multiple regression analyses.

Results: The prevalence of pre-diabetes and diabetes was $37.3 \%$ and $22.8 \%$, respectively. Fifty-six percent of diabetic cases were undiagnosed and $85 \%$ of diagnosed diabetic cases had poor glycemic control. Participants from rural areas and from southern parts of the country had higher infection rates, with Opisthorchis viverrini, being the most common helminth infection (30.5\%). We found a positive association between Taenia spp. infections and HbA1c ( $\beta=0.117 ; 95 \% \mathrm{Cl}$ : $0.042-0.200)$ and diabetes mellitus risk $(O R=2.98 ; 95 \%$ Cl: 1.10-8.05). No other helminth species was associated with glycated hemoglobin.

(Continued on next page)
}

\footnotetext{
* Correspondence: nicole.probst@swisstph.ch

${ }^{1}$ Department of Epidemiology and Public Health, Swiss Tropical and Public

Health Institute, PO Box, 4002, 4051 Basel, Switzerland

${ }^{2}$ University of Basel, Basel, Switzerland

Full list of author information is available at the end of the article
}

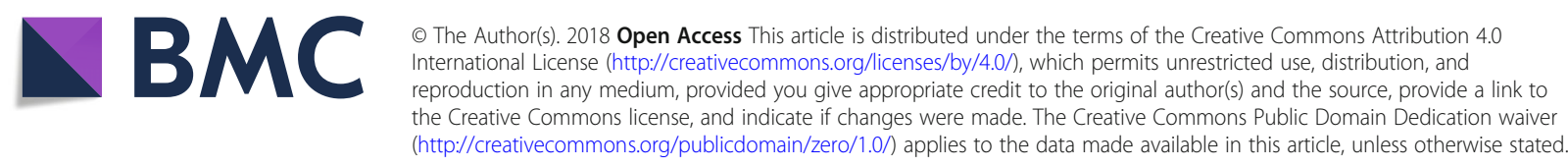




\begin{abstract}
(Continued from previous page)
Conclusions: Hyperglycaemia and diabetic rates in Lao PDR are alarmingly high, but consistent with other high rates in the region. Given the high rates of under-diagnosis and poorly-controlled glycaemia in diabetes mellitus patients, routine diabetes screening and treatment is essential for the local healthcare system. Large longitudinal cohorts integrating biomarkers are warranted in the search of causal diabetes mellitus risk factors in the region. Common intestinal helminth infections, including $O$. viverrini, are unlikely to explain the high diabetes mellitus rates observed.
\end{abstract}

Keywords: Dual burden of disease, Opisthorchis viverrini, Taenia, Diabetes mellitus, Cross-sectional, Epidemiology, Adults, Lao PDR

\section{Multilingual abstract}

Please see Additional file 1 for translation of the abstract into the five official working languages of the United Nations

\section{Background}

Most low- and middle- income countries (LMICs) are faced with challenges arising from demographic aging and lifestyle changes along with economic development, resulting in an increasing prevalence of non-communicable diseases (NCDs). An estimated 415 million people are currently living with diabetes mellitus (DM) worldwide, and the number is estimated to increase to 642 million in 2040 [1]. Similarly, the infectious disease (ID) burden in these countries also remains high. Approximately, 24\% of the world's population (more than 1.5 billion people) is infected with one or more species of helminth infections [2]. The population of the Lao People's Democratic Republic (Lao PDR) is affected by even higher rates of helminth infections, as a result of high rates of soil-transmitted helminths (STH) such as hookworm (87\%), Trichuris trichiura (33\%), Ascaris lumbricoides (3\%) and Strongyloides stercoralis (45\%) [3-6]. Foodborne trematode infections are endemic in all provinces in Lao PDR, however rates are particularly high in the southern provinces and frequently reach $50 \%$ and above [7]. In a study in the province of Saravane, the prevalence of Taenia spp. at the village level reached a prevalence of $12 \%$ [8]. According to the World Health Organisation (WHO) Lao PDR country profile, 2016, the prevalence of DM in the total population is estimated at $5.6 \%$, and is expected to increase considerably in the near future [9].

Recent epidemiological discoveries have pointed to a potential role of helminth infections in the aetiology of diabetes. Many helminths have evolved to live in human organisms for long periods of time. The strategy against being expelled involves a cross-talk with human innate and adaptive immune responses, which may be mediated in part by alterations in the gut microbiome. The inverse relationship between helminth infections and risk of metabolic disorders has been named "metabolic hygiene hypothesis", after the framework of the hygiene hypothesis for the association between early childhood infections and allergies. Furthermore, inflammation is an established etiological factor for insulin resistance, a precursor phenotype on the pathway to DM [10]; however, the metabolic hygiene hypothesis has not been commonly tested. The objective of this study was therefore, to evaluate the epidemiological association of specific helminthic infections with glycaemia and DM in adults from the Lao PDR.

\section{Methods}

\section{Study setting and sample size}

A total of 1600 adults aged 35 years and older were recruited in four areas of Lao PDR, each consisting of urban as well as rural sites from the provinces of Vientiane (the Vientiane capital and Pakgneum district), Luang Prabang (LP city and Namback district), Saravane (Saravane city and Saravane district), and Champasack (Pakse city and Kong district), between March and April, 2016. Study subjects were randomly recruited among inhabitants if they had been living in the selected study areas for the last five years. We assumed a $20 \%$ parasitic infection rate in the study area. With 186 enrolled individuals the infection rate could be assessed with a $95 \%$ confidence interval $(C I)$. We compensated for an expected non-optimal compliance by adding $10 \%$ to the sample calculated size. Therefore, 200 persons were enrolled in each of the 4 study areas. Data collection took place in March-April 2016. All 1600 participants answered a questionnaire, had a clinical examination and blood taken through finger prick. They also provided two stool samples each. The data collectors were first year master students from the Francophone Institute for Tropical Medicine (IFMT), Vientiane, Lao PDR (today named International Program for Health in the Tropics, now integrated in the Lao Tropical and Public Institute [Lao TPHI] in Vientiane) who had undergone a rigorous training for each segment of data collection.

\section{Questionnaire and clinical information}

Each participant was assigned a specific six-digit identification number, reflecting the study site, the village and the household number. A semi-structured questionnaire was developed to collect information on socio-demographic factors, risk factors for chronic diseases, previous and current health problems, as well as knowledge and perception of 
diseases of interest for the study. The questionnaire was translated from English to the local language for the interviews.

The clinical examination included a general assessment of the participant's health status, including the measurement of arterial blood pressure, height, weight, waist and hip circumference, as well as haemoglobin and glycated haemoglobin (HbA1c) in capillary blood.

Blood pressure was measured three times over an interval of five minutes between each reading using the Omron M6 AC (Hoofdoorp, Netherlands) upper arm digital blood pressure monitor. Participants were seated for $15 \mathrm{~min}$ before the blood pressure assessment and the mid-arm circumference was also measured with the use of an appropriate semi-rigid preformed arm cuff. The mean systolic and diastolic blood pressure readings were noted.

Height was measured using a SECA 206 roll-up measuring tape with wall attachment. (SECA $\mathrm{GmbH} \& \mathrm{Co}$. KG, Hamburg, Germany) The height was recorded in centimetres with one decimal.

Weight was measured using the non-automatic personal scale, SECA 877 (SECA GmbH \& Co. KG, Hamburg, Germany). Participants were asked to take off shoes, coat and heavy clothes before being weighed. The weight was recorded with one decimal.

Waist and hip circumference was measured using the SECA 203 measuring tape (SECA GmbH \& Co. KG, Hamburg, Germany). The waist circumference measured was the area between the ribs and iliac crest, and the hip circumference was the maximum circumference between the iliac crest and the crotch. Measurements were recorded in centimetres with one decimal.

Haemoglobin level was measured using the point-of-care anaemia screening, HemoCue $\mathrm{Hb} 301$ System (HemoCue $\mathrm{AB}$, Ängelholm, Sweden). Results were reported to the nearest $0.1 \mathrm{~g} / \mathrm{L}$.

Glycated haemoglobin (HbA1c)/DM status assessment: HbA1c values reflect plasma glucose concentration over an eight to 12 weeks period before the measurement. It is a convenient screening test for diabetes as there is no fasting requirement. HbA1c concentration in blood obtained by a finger-prick test was measured using the point-of-care instrument Afinion AS 100 analyser and cartridges (Alere Inc. Waltham, Massachusetts, USA). The cut-offs of the American Diabetes Association [11] were applied: normal: <5.7; pre-DM: 5.7-6.4; and DM: $\geq 6.5$. Subjects which self-reported a diagnosis and treatment of DM were classified as DM, irrespective of their HbA1c blood concentration. DM categories were further subdivided into diagnosed and treated DM; diagnosed DM, but untreated DM and undiagnosed DM. Newly diagnosed DM cases with HbA1c levels $\geq 6.5 \%$ were referred to a health clinic or hospital for confirmation of DM.

\section{Parasitological examination}

Two faecal samples were collected consecutively for two days for each participant and fixed in $10 \%$ formalin. The fixed samples were sent to the microbiology laboratory at Khon Kaen University, Khon Kaen, Thailand, in which, the formalin ether concentration technique (FECT) was used for helminth diagnosis.

\section{Data management and analysis}

Data was double-entered and subjected to validation checks using EpiData 3.1 (EpiData Association, Odense, Denmark). A complete case analysis (individuals with stool samples, HbA1c results, and complete covariate information) was conducted to investigate the association of explanatory variables (helminths; covariates) with the outcome variable (HbA1c; DM) using STATA 14.1 (StataCorp; College Station, TX, USA). Descriptive statistics of the participants characteristics were reported as frequencies and percentages for categorical variables and means and standard deviations (SD) for continuous variables. The sex-stratified DM categories according to the measured HbAlc concentrations were cross-tabulated with self-reported DM diagnosis and treatment. The helminth infection prevalence was stratified by study sites as well as the type of study area (rural vs urban). The distribution of covariates and helminth infections was presented separately for non-DM (non self-reported DM; normal HbA1c), pre-DM (non self-reported DM; pre-DM HbA1c), and DM groups (self-reported DM diagnosis or diabetic HbA1c). The socio-economic status (SES) of participants was estimated using a household-based asset approach. SES scores were constructed using principle component analysis (PCA). Participants were categorized into three groups; poorest, second poorest and least poorest [12]. Chi-square $\left(\chi^{2}\right)$ tests and analysis of variance tests were conducted to investigate the unadjusted association between covariates and DM categories. Linear (outcome HbA1c measurements) and logistic (outcome DM status) regression models with random intercepts of study sites were performed to explore the independent relationship between helminth infections and $\mathrm{HbA1c}$ measurements and diabetes, respectively. Participants self-reporting a physician diagnosis of DM and medical DM treatment $(N=54)$ were excluded from these regression analyses. The regression models were adjusted for a set of preselected potential confounders (study sites, age, sex, educational level, SES status, alcohol consumption, smoking status, haemoglobin levels, body mass index [BMI] and physical inactivity). A two-sided $P$ value $<0.05$ was considered as a statistically significant level.

\section{Results}

Among the 1604 participants, 1528 (95.3\%) were considered in the analysis. The observed prevalence of pre-diabetes and diabetes was $37.3 \%$ and $22.8 \%$, 
respectively (Fig. 1). Table 1 summarizes the total and sex-stratified distribution of DM and pre-DM according to HbA1c levels, both, for the entire study sample and stratified by self-reported DM diagnosis and treatment. Among the total sample, 614 participants had HbA1c values in the normal range, in which, five self-reported $\mathrm{DM} ; 585$ in the pre-DM range, in which, 15 self-reported DM; and 329 in the DM range, in which, 135 self-reported DM. The distribution of DM categories did not differ considerably between males and females. Fifty-six percent $(n=194)$ participants from a total of 349 participants with DM were unaware of their disease (Fig. 1). Among the 155 participants self-reporting a DM diagnosis, only $39 \%(n=61)$ reported some kind of treatment, while only $35 \% \quad(n=54)$ reported intake of physician-prescribed anti-diabetic treatment. In more than $85 \%$ of patients with self-reported DM, irrespective of undergoing treatment or not, HbA1c concentrations measured were still in the diabetic range.

Table 2 shows the prevalence of helminth infections stratified by rural and urban areas as well as by the four study provinces. Helminth infections were more frequent in rural areas compared to urban areas and in the two southern provinces compared to the two Northern provinces. The two southern provinces in Lao PDR and along the Mekong River (Saravane and Champasack) had overall infection rates of $49 \%$ and $44.9 \%$, respectively, mostly due to O. viverrini ( $43 \%$ and $40 \%$, respectively). In fact, $O$. viverrini was the most frequent trematode followed by minute intestinal flukes and Paragonimus spp. with prevalence rates of $30.5 \%, 6.3 \%$ and $0.3 \%$, respectively. The overall nematodes infection rates were $7.7 \%$ including hookworm (4.8\%), S. stercoralis (2.6\%), T. trichiura (0.5\%) and $A$. lumbricoides (0.3\%), respectively. We also found an infection rate of $2.2 \%$ for Taenia spp.

Table 3 compares the characteristic of participants and helminth infection rates across DM status categories, defined by the combination of self-reported DM and HbA1c concentration. The mean age of participants was 54.9 years (SD: 12.0 years, range: $35-95$ years), $70 \%$ were women, $50 \%$ lived in rural settings, $94 \%$ belonged to the Lao ethnic group, $16 \%$ were illiterate and $31 \%$ belonged to the poorest category. With regard to lifestyle factors, $32 \%$ reported to be ever smokers, $48 \%$ to be ever alcohol

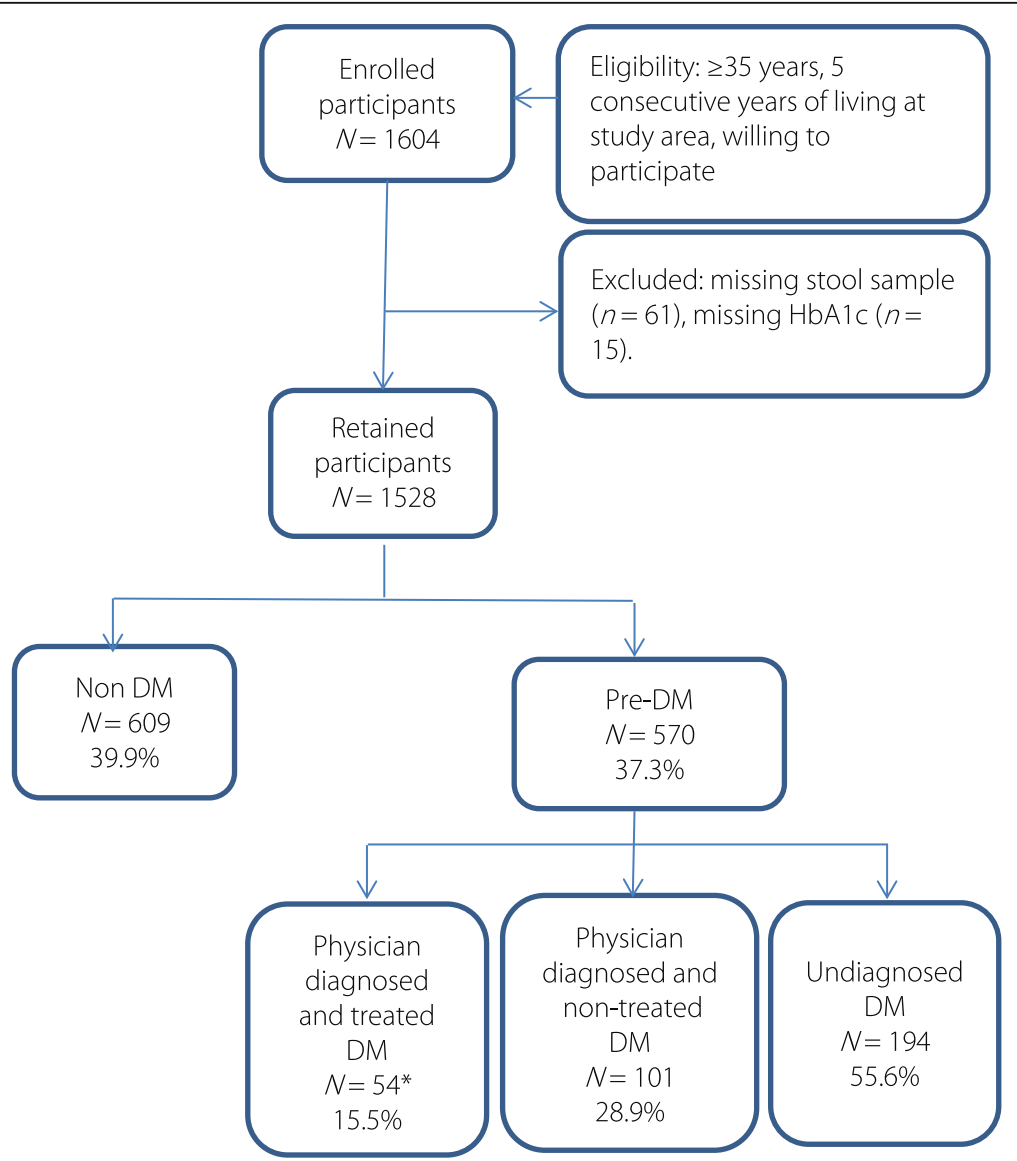

Fig. 1 Flow chart of the study sample and distribution of pre-diabetes and diabetes. \#categorization based on a positive self-report of DM diagnosis and otherwise based on the HbA1c concentrations. *subjects self-reporting a physician diagnosis and taking DM medication were excluded from multivariable regression models on the association between infections and HbA1c or DM. DM: Diabetes mellitus 
Table 1 Diabetes status according to HbA1c measurements, stratified by sex, self-reported diabetes diagnosis and treatment status

\begin{tabular}{|c|c|c|c|}
\hline $\begin{array}{l}\text { DM category according } \\
\text { to HbAlc level }\end{array}$ & $\begin{array}{l}\text { Total } \\
N(\%)\end{array}$ & $\begin{array}{l}\text { Male } \\
N(\%)\end{array}$ & $\begin{array}{l}\text { Female } \\
N(\%)\end{array}$ \\
\hline \multicolumn{4}{|l|}{ All study participants $(N=1528)$} \\
\hline Normal & $614(40.2)$ & $183(40.9)$ & $431(39.9)$ \\
\hline Pre-DM & $585(38.3)$ & $165(36.8)$ & $420(38.9)$ \\
\hline DM & $329(21.5)$ & $100(22.3)$ & $229(21.2)$ \\
\hline Mean (Standard Deviation) & $6.4(1.9)$ & $6.4(1.9)$ & $6.4(1.9)$ \\
\hline \multicolumn{4}{|l|}{ Self-reported DM cases $(N=155)$} \\
\hline Normal & $5(3.2)$ & $3(6.1)$ & $2(1.9)$ \\
\hline Pre-DM & $15(9.7)$ & $3(6.1)$ & $12(11.3)$ \\
\hline DM & $135(87.1)$ & $43(87.7)$ & $92(86.8)$ \\
\hline \multicolumn{4}{|c|}{ Self-reported DM cases with any treatment $(N=61)$} \\
\hline Pre-DM & $8(13.1)$ & $0(0)$ & $8(17.0)$ \\
\hline DM & $53(86.9)$ & $14(100)$ & $39(83.0)$ \\
\hline \multicolumn{4}{|c|}{$\begin{array}{l}\text { Self-reported DM cases with a physician diagnosis and currently taking } \\
\text { DM drugs }(N=54)\end{array}$} \\
\hline Pre-DM & $7(13.2)$ & $0(0)$ & $7(17.1)$ \\
\hline DM & 46 (86.8) & $12(100)$ & 34 (82.9) \\
\hline
\end{tabular}

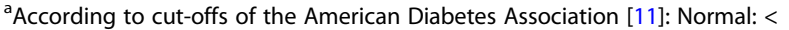
5.7; Pre-DM: 5.7-6.4; DM: $\geq 6.5$

$D M$, Diabetes mellitus, $\mathrm{HbA1c}$ Glycated haemoglobin drinkers and $19 \%$ to be physically inactive. The mean waist circumference was $82.8 \mathrm{~cm}$ in men and $80.7 \mathrm{~cm}$ in women (recommended cut-off points for Asians: $90 \mathrm{~cm}$ in men and $80 \mathrm{~cm}$ in women) [13]. The mean $\mathrm{Hb}$ concentration was $131.3 \mathrm{mg} / \mathrm{dl}$ in men and $119.1 \mathrm{mg} / \mathrm{dl}$ in women (WHO cut-off points for non-anaemic $\mathrm{Hb}$ values are $\geq 130 \mathrm{~g} / \mathrm{L}$ (male); $\geq 110 \mathrm{~g} / \mathrm{L}$ (female)). As expected, participants with DM were more likely to be older, to be of higher socio-economic status and to score higher on the anthropometric parameters including BMI, waist circumference, hip circumference and waist-hip ratio. Participants without diabetes exhibited the highest overall infection, with trematode and O. viverrini among this unadjusted comparison, whereas there was a tendency for Taenia spp. to be more common in subjects with DM.

Table 4 shows the independent associations of infection groups and single infections with $\mathrm{HbA1c}$ in the study population after exclusion of subjects with physician-diagnosed and treated DM. Results are presented with and without adjustment for BMI and physical inactivity, which may in part be mediators of the association between helminth infections and HbAlc. Positive associations between Taenia spp. infections and HbA1c were observed, in both, models containing infection groups of single infections and models with and without adjustment for BMI and physical activity (largest effect estimate in model of infections groups and

Table 2 Prevalence ( $N$, prevalence) of helminth infections in the study area

\begin{tabular}{|c|c|c|c|c|c|c|c|}
\hline Helminth infections & $\begin{array}{l}\text { Total } \\
(N=1528)\end{array}$ & $\begin{array}{l}\text { Rural } \\
(n=766)\end{array}$ & $\begin{array}{l}\text { Urban } \\
(n=762)\end{array}$ & $\begin{array}{l}\text { Northern Province } \\
V^{\text {Vientiane }} \mathrm{a}^{\mathrm{a}} \\
(n=378)\end{array}$ & $\begin{array}{l}\text { Northern Province } \\
\text { Luang Prabang }^{\mathrm{a}} \\
(n=363)\end{array}$ & $\begin{array}{l}\text { Southern Province } \\
\text { Saravane }^{\mathrm{a}} \\
(n=396)\end{array}$ & $\begin{array}{l}\text { Southern Province } \\
\text { Champasack } \\
(n=391)\end{array}$ \\
\hline Any infection & $\begin{array}{l}539 \\
(35.3)\end{array}$ & $\begin{array}{l}332 \\
(43.3)\end{array}$ & $\begin{array}{l}207 \\
(27.2)\end{array}$ & $\begin{array}{l}113 \\
(29.9)\end{array}$ & $\begin{array}{l}58 \\
(16.0)\end{array}$ & $\begin{array}{l}193 \\
(48.7)\end{array}$ & $\begin{array}{l}175 \\
(44.8)\end{array}$ \\
\hline Any trematode infection & $\begin{array}{l}473 \\
(31.0)\end{array}$ & $\begin{array}{l}286 \\
(37.3)\end{array}$ & $\begin{array}{l}187 \\
(24.5)\end{array}$ & $\begin{array}{l}108 \\
(28.6)\end{array}$ & $\begin{array}{l}34 \\
(9.4)\end{array}$ & $\begin{array}{l}174 \\
(43.9)\end{array}$ & $\begin{array}{l}157 \\
(40.2)\end{array}$ \\
\hline Opisthorchis viverrini & $\begin{array}{l}466 \\
(30.5)\end{array}$ & $\begin{array}{l}282 \\
(36.8)\end{array}$ & $\begin{array}{l}184 \\
(24.1)\end{array}$ & $\begin{array}{l}106 \\
(28.0)\end{array}$ & $\begin{array}{l}33 \\
(9.1)\end{array}$ & $\begin{array}{l}171 \\
(43.2)\end{array}$ & $\begin{array}{l}156 \\
(39.9)\end{array}$ \\
\hline Minute intestinal flukes & $\begin{array}{l}96 \\
(6.3)\end{array}$ & $\begin{array}{l}71 \\
(9.3)\end{array}$ & $\begin{array}{l}25 \\
(3.3)\end{array}$ & $\begin{array}{l}8 \\
(2.1)\end{array}$ & $\begin{array}{l}0 \\
(0)\end{array}$ & $\begin{array}{l}45 \\
(11.4)\end{array}$ & $\begin{array}{l}43 \\
(11.0)\end{array}$ \\
\hline Paragonimus spp. & $\begin{array}{l}4 \\
(0.3)\end{array}$ & $\begin{array}{l}2 \\
(0.3)\end{array}$ & $\begin{array}{l}2 \\
(0.3)\end{array}$ & $\begin{array}{l}1 \\
(0.3)\end{array}$ & $\begin{array}{l}1 \\
(0.3)\end{array}$ & $\begin{array}{l}1 \\
(0.3)\end{array}$ & $\begin{array}{l}1 \\
(0.3)\end{array}$ \\
\hline Any nematode infection & $\begin{array}{l}117 \\
(7.7)\end{array}$ & $\begin{array}{l}87 \\
(11.4)\end{array}$ & $\begin{array}{l}30 \\
(3.9)\end{array}$ & $\begin{array}{l}5 \\
(1.3)\end{array}$ & $\begin{array}{l}26 \\
(7.2)\end{array}$ & $\begin{array}{l}52 \\
(13.1)\end{array}$ & $\begin{array}{l}34 \\
(8.7)\end{array}$ \\
\hline Hookworm & $\begin{array}{l}73 \\
(4.8)\end{array}$ & $\begin{array}{l}55 \\
(7.2)\end{array}$ & $\begin{array}{l}18 \\
(2.4)\end{array}$ & $\begin{array}{l}2 \\
(0.5)\end{array}$ & $\begin{array}{l}10 \\
(2.8)\end{array}$ & $\begin{array}{l}44 \\
(11.1)\end{array}$ & $\begin{array}{l}17 \\
(4.4)\end{array}$ \\
\hline Strongyloides stercoralis & $\begin{array}{l}40 \\
(2.6)\end{array}$ & $\begin{array}{l}28 \\
(3.7)\end{array}$ & $\begin{array}{l}12 \\
(1.6)\end{array}$ & $\begin{array}{l}2 \\
(0.5)\end{array}$ & $\begin{array}{l}12 \\
(3.3)\end{array}$ & $\begin{array}{l}9 \\
(2.3)\end{array}$ & $\begin{array}{l}17 \\
(4.3)\end{array}$ \\
\hline Ascaris lumbricoides & $\begin{array}{l}4 \\
(0.3)\end{array}$ & $\begin{array}{l}4 \\
(0.5)\end{array}$ & $\begin{array}{l}0 \\
(0.0)\end{array}$ & $\begin{array}{l}1 \\
(0.3)\end{array}$ & $\begin{array}{l}3 \\
(0.8)\end{array}$ & $\begin{array}{l}0 \\
(0)\end{array}$ & $\begin{array}{l}0 \\
(0)\end{array}$ \\
\hline Trichuris trichiura & $\begin{array}{l}7 \\
(0.5)\end{array}$ & $\begin{array}{l}5 \\
(0.7)\end{array}$ & $\begin{array}{l}2 \\
(0.3)\end{array}$ & $\begin{array}{l}0 \\
(0.0)\end{array}$ & $\begin{array}{l}4 \\
(1.1)\end{array}$ & $\begin{array}{l}2 \\
(0.5)\end{array}$ & $\begin{array}{l}1 \\
(0.3)\end{array}$ \\
\hline Cestodes (Taenia spp.) & $\begin{array}{l}34 \\
(2.2)\end{array}$ & $\begin{array}{l}25 \\
(3.3)\end{array}$ & $\begin{array}{l}9 \\
(1.2)\end{array}$ & $\begin{array}{l}12 \\
(3.2)\end{array}$ & $\begin{array}{l}3 \\
(0.8)\end{array}$ & $\begin{array}{l}13 \\
(3.3)\end{array}$ & $\begin{array}{l}6 \\
(1.5)\end{array}$ \\
\hline
\end{tabular}

${ }^{a}$ in each province participants from urban and rural sites were recruited 
Table 3 Participants characteristics according to DM categories $(N=1528)$

\begin{tabular}{|c|c|c|c|c|c|}
\hline \multirow[t]{2}{*}{ Covariates } & \multirow{2}{*}{$\begin{array}{l}\text { Total } \\
(N, \%)\end{array}$} & \multicolumn{3}{|c|}{ Categories of DM $(N, \%)^{a}$} & \multirow[t]{2}{*}{${ }^{*} P$-value } \\
\hline & & $\begin{array}{l}\text { No DM } \\
(n=609)\end{array}$ & $\begin{array}{l}\text { Pre-DM } \\
(n=570)\end{array}$ & $\begin{array}{l}\mathrm{DM} \\
(n=349)\end{array}$ & \\
\hline$\overline{\text { Age }}$ & & & & & $<0.001$ \\
\hline $35-49$ years & $535(35.0)$ & $303(49.7)$ & 163(28.6) & $69(19.8)$ & \\
\hline $50-60$ years & $534(34.9)$ & $177(29.1)$ & 199(34.9) & 158(45.3) & \\
\hline $61-95$ years & $459(30.1)$ & $129(21.2)$ & 208(36.5) & 122(34.9) & \\
\hline Mean, SD & $54.9(12.0)$ & & & & \\
\hline Female (\%) & $1080(70.7)$ & $429(70.4)$ & 408(71.6) & 243(69.6) & 0.83 \\
\hline Rural (\%) & $766(50.1)$ & $322(52.9)$ & $276(48.4)$ & 168(48.1) & 0.12 \\
\hline Ethnicity (Lao) & 1438(94.1) & $564(92.6)$ & $540(94.7)$ & $334(95.7)$ & 0.59 \\
\hline Education & & & & & 0.05 \\
\hline Illiterate & $247(16.2)$ & $80(13.1)$ & 105(18.4) & $62(17.8)$ & \\
\hline Primary level & $719(47.0)$ & $286(47.0)$ & $270(47.4)$ & 163(46.7) & \\
\hline Secondary level & $562(36.8)$ & 243(39.9) & 195(34.2) & $124(35.5)$ & \\
\hline Socio-economic status & & & & & 0.002 \\
\hline Poorest & $505(33.1)$ & $219(36.0)$ & 199(34.9) & $87(24.9)$ & \\
\hline Second least poorest & $514(33.6)$ & 208(34.1) & 186(32.6) & $120(34.4)$ & \\
\hline Least poorest & 509(33.3) & 182(29.9) & 185(32.5) & $142(40.7)$ & \\
\hline Ever smokers & $491(32.1)$ & 196(32.2) & 177(31.1) & 118(33.8) & 0.64 \\
\hline Ever alcohol drinkers & $733(48.0)$ & $354(58.1)$ & 244(42.8) & 135(38.7) & $<0.001$ \\
\hline No physical activity & 288(18.8) & 112(18.4) & $122(21.4)$ & $54(15.5)$ & 0.13 \\
\hline Weight (kg; mean, SD) & $58.1(11.9)$ & $55.6(11.0)$ & $58.3(11.8)$ & $61.9(12.5)$ & $<0.001$ \\
\hline Height (cm; mean, SD) & 153.6(7.2) & 153.8(7.1) & 153.0(7.1) & $154.0(7.4)$ & 0.08 \\
\hline BMI $\left(\mathrm{kg} / \mathrm{m}^{2} ;\right.$ mean, SD) & $24.6(4.5)$ & $23.5(4.1)$ & $24.8(4.5)$ & $26.0(4.5)$ & $<0.001$ \\
\hline Hip circumference (cm; mean, SD) & $93.2(10.0)$ & $91.0(9.7)$ & $94.1(10.0)$ & $95.8(9.7)$ & $<0.001$ \\
\hline Waist circumference(cm; mean, SD) & $81.2(11.8)$ & 77.4(10.8) & $82.3(11.7)$ & $86.5(11.2)$ & 0.12 \\
\hline Waist-hip ratio (mean, SD) & $0.87(0.07)$ & $0.85(0.06)$ & $0.87(0.06)$ & $0.90(0.06)$ & $<0.001$ \\
\hline Hb concentration (mg/dl; mean, SD) & $122.7(17.8)$ & $122(18)$ & $123(18)$ & 125(18) & 0.04 \\
\hline \multicolumn{6}{|l|}{ Helminth infections } \\
\hline Any infection & $513(33.6)$ & $224(36.8)$ & 189(33.2) & $100(28.7)$ & 0.04 \\
\hline Any trematode infection & $473(31.0)$ & $211(34.6)$ & 175(30.7) & $87(24.9)$ & 0.03 \\
\hline Opisthorchis viverrini & $466(30.5)$ & $207(34.0)$ & 169(29.6) & $90(25.8)$ & 0.03 \\
\hline Minute intestinal flukes & $96(6.3)$ & $37(6.1)$ & $41(7.2)$ & $18(5.2)$ & 0.62 \\
\hline Paragonimus spp. & $4(0.3)$ & $1(0.2)$ & $2(0.3)$ & $1(0.3)$ & 0.82 \\
\hline Any nematode infection & $117(7.7)$ & $51(8.4)$ & $49(8.4)$ & $17(4.9)$ & 0.16 \\
\hline Hookworm & $73(4.8)$ & $34(5.6)$ & $25(4.4)$ & $14(4.0)$ & 0.23 \\
\hline Strongyloides stercoralis & $40(2.6)$ & $13(2.1)$ & $21(3.7)$ & $6(1.7)$ & 0.15 \\
\hline Ascaris lumbricoides & $4(0.3)$ & $2(0.3)$ & $2(0.3)$ & $0(0.0)$ & 0.56 \\
\hline Trichuris trichiura & $7(0.5)$ & $4(0.7)$ & $3(0.5)$ & $0(0.0)$ & 0.34 \\
\hline Cestodes/Taenia spp. & $34(2.2)$ & 10(1.6) & $11(1.9)$ & $13(3.7)$ & 0.08 \\
\hline
\end{tabular}

* $P$-value comparing the distribution of the respective factor between DM categories ${ }^{a}$ categorization based on a positive self-report of DM diagnosis and otherwise based on the HbA1c concentrations DM Diabetes mellitus 
Table 4 Independent association of single infections and infection groups with HbA1c in all participants ${ }^{a}$

\begin{tabular}{|c|c|c|c|c|}
\hline \multirow[t]{2}{*}{ Infections } & \multicolumn{2}{|c|}{$\begin{array}{l}\text { Adjusted for other infections, study site, age, sex, SES status, education status, } \\
\text { smoking status, alcohol consumption and haemoglobin level }\end{array}$} & \multicolumn{2}{|c|}{$\begin{array}{l}\text { Additionally adjusted for BMI and } \\
\text { physical inactivity }\end{array}$} \\
\hline & $\beta$ & $95 \% \mathrm{Cl}$ & $\beta$ & $95 \% \mathrm{Cl}$ \\
\hline \multicolumn{5}{|c|}{ Grouped infections ${ }^{\mathrm{b}}(N=1474)$} \\
\hline Nematodes & -0.040 & $-0.081-0.002$ & -0.035 & $-0.076-0.006$ \\
\hline Trematodes & -0.003 & $-0.027-0.021$ & -0.0003 & $-0.023-0.024$ \\
\hline $\begin{array}{l}\text { Cestodes } \\
\text { Taenia spp. }\end{array}$ & 0.112 & $0.037-0.188$ & 0.117 & $0.042-0.200$ \\
\hline \multicolumn{5}{|c|}{ Single infection ${ }^{c}(N=1466)^{d}$} \\
\hline Hookworm & -0.030 & $-0.083-0.021$ & -0.025 & $-0.076-0.027$ \\
\hline Opisthorchis viverrini & -0.009 & $-0.035-0.017$ & -0.002 & $-0.025-0.022$ \\
\hline Minute intestinal flukes & 0.021 & $-0.028-0.069$ & 0.011 & $-0.034-0.056$ \\
\hline Strongyloides stercoralis & -0.043 & $-0.128-0.014$ & -0.046 & $-0.116-0.024$ \\
\hline Trichuris trichiura & -0.043 & $-0.202-0.115$ & -0.063 & $-0.220-0.094$ \\
\hline Taenia spp. & 0.114 & $0.039-0.190$ & 0.116 & $0.042-0.192$ \\
\hline
\end{tabular}

a Participants excluding participants self-reporting a physician-diagnosis of DM and intake of DM medication

bModel including infection groups nematodes (yes vs no), trematode infection (yes vs. no), and cestodes (yes vs no)

'Model including single infections hookworm (yes vs no), O. viverrini (yes vs no), minute intestinal flukes (yes vs no), Strongyloides stercoralis (yes vs no), Trichuris

trichiura (yes vs no) and Taenia spp./cestodes (yes vs no)

${ }^{\mathrm{d} S u b j e c t s}$ with other rare types of infections were excluded from this analysis

Cl: Confidence interval

adjusting for BMI and physical activity: $\beta=0.117$; $95 \%$ CI: $0.042-0.200$ ). Interestingly, this positive association seems to be driven by an association with $\mathrm{HbA1c}$ in the diabetic range. In healthy subjects without pre-DM or DM, we found an inverse relationship between Taenia spp. and HbA1c measurements ( $\beta=-0.049$; 95\% CI: $-0.075-0.022$ ) (Additional file 2). No association of HbA1c with any other infection or infection group was observed.

Table 5 shows the independent associations of single helminth infections with DM compared to non-DM after excluding subjects with a self-reported physician diagnosis of DM and intake of DM medication, and leaving the pre-DM category out. Results are again presented with and without adjustment for BMI and physical inactivity. Consistent with our findings on the infection-HbA1c associations, we found that having a Cestode infection, but not any other infections was associated with an increased risk of DM (Adjusted OR $=2.98,95 \%$ CI: 1.10-8.05). The independent association of other factors with DM risk in the expected directions validate the assessment of DM and HbA1c: age $(O R=1.05,95 \% C I$ : 1.04-1.08), being male $(O R=1.42,95 \% C I: 0.89-2.00)$, highest socio-economic status $(O R=1.70,95 \% C I$ : $1.08-2.67)$, ever smoker $(O R=1.89,95 \% C I: 1.22-2.92)$, and exhibiting high $\mathrm{Hb}$ concentration $(O R=1.02,95 \% C I: 1.15-1.25)$, and high BMI $(O R=1.20,95 \% C I: 1.15-1.25)$. Interestingly, self-reported alcohol consumption $(O R=0.54,95 \% C I$ : $0.38-0.76)$ was inversely associated with DM risk. These results did not substantially change when pre-DM and DM were jointly compared to the pre-DM or DM group (Additional file 3).

\section{Discussion}

We found alarmingly high rates of DM and pre-DM in this adult study population in Lao PDR. Local populationbased HbA1c findings for comparison are not available in Lao PDR, however, the prevalence found in this study is consistent and comparable to that of the province of Guangdong, an economically well-developed and urbanized area in Southern China, in which the prevalence is $22 \%$ [14]. The study in China estimated the diabetes prevalence based on a combination of self-reported DM, $\mathrm{HbA1c}$ measured in capillary finger-prick blood as well as venous blood fasting glucose and glucose tolerance testing. This suggests that the observed DM prevalence in Lao PDR, may even be higher than reported here as adding glucose to the DM screening tests results in the identification of additional cases [14, 15]. The high pre-DM and DM rates with a tendency for earlier onset in Asian populations remain partly unexplained [16]. According to the results of this current study common helminth infections in Lao PDR may not explain the high DM and pre-DM prevalences.

The current findings on the prevalence and distribution of helminth infections are consistent with previous studies in Lao PDR. Multiple helminth infections of different trematode, nematodes and cestode species were also common as documented in previous literature [17-20]. The high prevalence rates of the trematode infection, particularly with $O$. viverrini, is consistent with previous studies [21]. Minute intestinal flukes and hookworm were also very frequently diagnosed. These helminths are generally more common in Lao PDR and the Mekong sub-region 
Table 5 Independent association of single infections with DM compared to non-DM, with and without adjustment for BMI and physical inactivity in all participants $\left(N=892^{\mathrm{a}}\right)$

\begin{tabular}{|c|c|c|c|c|c|c|}
\hline DM status compared to Normal ${ }^{b}$ & $O R^{C}$ & $95 \% \mathrm{Cl}$ & $P$-value & $O R^{d}$ & $95 \% \mathrm{Cl}$ & $P$-value \\
\hline Hookworm & 0.79 & $0.36-1.72$ & 0.56 & 0.94 & $0.42-2.10$ & 0.88 \\
\hline Opisthorchis viverrini & 0.76 & $0.52-1.10$ & 0.15 & 0.87 & $0.58-1.28$ & 0.46 \\
\hline Minute intestinal flukes & 1.38 & $0.68-2.78$ & 0.37 & 1.20 & $0.57-2.52$ & 0.63 \\
\hline Strongyloides stercoralis & 0.65 & $0.19-2.30$ & 0.51 & 0.65 & $0.15-2.72$ & 0.55 \\
\hline Trichuris trichiura & 1.00 & Omitted & & 1.00 & Omitted & \\
\hline Taenia spp. & 2.59 & $0.98-6.87$ & 0.06 & 2.98 & $1.10-8.05$ & 0.03 \\
\hline \multicolumn{7}{|l|}{ Study sites(Vientiane as reference) } \\
\hline Lung Prabang & 0.75 & $0.47-1.20$ & 0.24 & 0.80 & $0.48-1.31$ & 0.37 \\
\hline Saravane & 0.74 & $0.47-1.28$ & 0.32 & 0.89 & $0.52-1.51$ & 0.66 \\
\hline Champasack & 0.76 & $0.48-1.20$ & 0.24 & 0.85 & $0.52-1.39$ & 0.53 \\
\hline \multicolumn{7}{|c|}{ Socio-economic status(Poorest as reference) } \\
\hline Second least poorest & 1.51 & $1.00-2.27$ & 0.04 & 1.30 & $0.84-1.99$ & 0.24 \\
\hline Least poorest & 2.16 & $1.42-3.31$ & $<0.001$ & 1.70 & $1.08-2.67$ & 0.02 \\
\hline Age & 1.05 & $1.04-1.07$ & $<0.001$ & 1.05 & $1.04-1.08$ & $<0.001$ \\
\hline Gender (Male) & 1.64 & $1.05-2.56$ & 0.03 & 1.42 & $0.89-2.27$ & 0.14 \\
\hline \multicolumn{7}{|l|}{ Education(Illiterate as reference) } \\
\hline Primary & 0.92 & $0.57-1.47$ & 0.72 & 0.71 & $0.43-1.18$ & 0.19 \\
\hline Secondary & 0.85 & $0.49-1.45$ & 0.55 & 0.69 & $0.39-1.21$ & 0.20 \\
\hline Ever smokers & 1.53 & $1.01-2.32$ & 0.04 & 1.89 & $1.22-2.92$ & 0.004 \\
\hline Ever alcohol drinkers & 0.54 & $0.38-0.76$ & $<0.001$ & 0.48 & $0.33-1.03$ & $<0.001$ \\
\hline $\mathrm{Hb}$ concentration & 1.02 & $1.01-1.03$ & $<0.001$ & 1.02 & $1.01-1.03$ & 0.002 \\
\hline$+\mathrm{BMl}$ & - & - & - & 1.20 & $1.15-1.25$ & $<0.001$ \\
\hline + Physical activity & - & - & - & 1.19 & $0.76-1.87$ & 0.45 \\
\hline
\end{tabular}

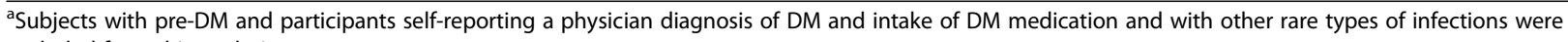
excluded from this analysis

${ }^{\mathrm{b} C}$ Categorization based on a positive self-report of DM diagnosis and otherwise based on the HbA1c concentrations

${ }^{\mathrm{c}}$ Mutually adjusted for variables listed

${ }^{\mathrm{d}}$ Additionally adjusted for BMI and physical inactivity

$\mathrm{Cl}$ Confidence interval, OR Odd ratio, BMI Body mass index, DM Diabetes mellitus

$[19,22]$. In our study we found $2.2 \%$ participants infected with Taenia spp., which is in general a rather high rate but comparable to previous observations from our team [23]. The national deworming program from the Ministry of Health implements biannual treatment of soil-transmitted helminths in school-children in collaboration with the ministry of education. In recent years, several rounds of mass-treatment were conducted with praziquantel in selected districts of Southern Lao PDR. While these control measures have had a considerable impact on the infection rates of soil-transmitted helminths, the prevalence of liver fluke infections were not reduced.

We have previously reported highly prevalent liver pathologies in rural Lao PDR, as documented by an ultrasound-based study in Saravane province, one of the current study areas [24]. We associated severe liver morbidity with $O$. viverrini [21], known to be a main risk factor for cholangiocarcinoma $[25,26]$. The absence of an association between $O$. viverrini infection and DM risk, suggests that $O$. viverrini related liver pathology may not contribute to DM development and the high rate of hyperglycaemia. In contrast, fatty liver disease, especially non-alcoholic fatty liver disease, is viewed as hepatic manifestation of the metabolic syndrome, is associated with insulin resistance, and was previously found to be an independent predictor of incident type 2 DM [27], due to chronic inflammation of the liver or hepatokine secretion. Fatty liver disease and $O$. viverrini associated liver pathology are different entities, which can in principle be differentiated by ultrasound, but the histological examination of liver biopsies remains the diagnostic gold standard. The independent and combined effects of $O$. viverrini infections, associated liver pathologies and fatty liver disease on incident DM need further investigation as the interactions are likely complex and possible in opposite directions. Future studies should also consider $O$. viverrini related modifications of the gut microbiome given the strong evidence for its relation to type 2 DM $[28,29]$. 
Both HbA1c and DM status were positively associated with Taenia spp. infection. Taeniasis is an intestinal parasitic infection and is acquired by the consumption of raw or undercooked meat (pork or beef) [30]. It is common in developing countries of Latin America, Asia, and Africa, and associated with poor hygienic and sanitary conditions (inadequate use of latrines or open-air defecation, traditional pig farming, lack of regulation on meat inspection and inadequate water supply) [30]. Taenia spp. infection is listed as one of the 17 neglected zoonotic diseases by WHO, which can be preventable and treatable. Individuals with intestinal Taenia infection are usually asymptomatic. T. solium is the cause of cysticercosis if parasite eggs are faecal-orally acquired. Cysticercosis may lead to a severe disease, particularly if the central neural system (neurocysticercosis) is affected [31]. There was no diagnosis of cysticercosisin our study sample.. All taeniasis patients in our study had a history of raw meat consumption $(92 \%$ beef and 32\% pork). People infected came mostly from rural areas of Vientiane and Saravane provinces. Co-infections with other helminths were also detected in half of Taenia sp. infected individuals, mostly with $O$. viverrini and/or minute intestinal flukes, hookworm and S. stercoralis. One study examining the effect of immune modulation induced by Taenia crassiceps infection on the outcome of multiple low dose of Streptozotocin-induced diabetes (MLDS) reported that $T$. crassiceps infection might protect against MLDS, irrespective of the host's genetic background. To the best of our knowledge, this is the first study to report an association between Taenia sp. infection and DM as well as HbA1c.

A limited number of studies have started to explore the interrelation between helminth infections and diabetes. Endemic helminth infections are thought and in part shown to affect insulin sensitivity and resistance through immune-modulating properties and by reducing energy intake and altering energy balance [32]. Yet, epidemiological evidence remains poor, and inconsistent, and points to infection-specific associations with DM. Some previous studies have reported a negative association between soil-transmitted helminth infections and insulin resistance [33], between filarial infection and type 1 and type 2 DM [34], and between Schistosoma japonicum infections and type 2 DM [35]. An infection with S. stercoralis was found positively associated with severe DM [36]. We reported a positive association of $H$. pylori infections with HbA1c in school children from poor neighbourhoods in South Africa, but neither a cross-sectional association with other common helminth infections nor a change in HbA1c as a result of anti-helminthic treatment [37]. It has been shown that socioeconomic, environmental and behavioural factors influence the prevalence and intensity of helminth infections and could therefore, in part, be confounders as well as mediators of any association with diabetes [18, 38]. It is thus, important to consider the recently published results from the first randomized placebo-controlled SUGARSPIN trial, investigating the effect of anthelmintic treatment on whole-body insulin sensitivity in a large Indonesian population sample [39]. Albendazole treatment had no effect among participants without any or only a single species helminth infection measured (hookworm [Ancylostoma duodenale, Necator americanus]; A. lumbricoides; $T$. trichiura; Strongyloides stercoralis), but resulted in high homeostatic model of insulin resistance, a measure of insulin resistance, in the presence of multiple species infection at baseline. No effect on HbA1c was observed, though.

Our study has a number of strengths. First, this is the only study to date assessing DM prevalence in Lao PDR, based on Hbalc measurements. Participants from the rural and urban area of the provinces located in the middle and southern part of the country were included; therefore, the findings reflect the prevalence of helminths and DM status of different populations from different geographical settings. Access to curative health services is very low in rural settings. Therefore, our results underline the needs for peripheral curative health services for DM diagnosis and management. Second, no previous study investigated the dual burden of diseases of DM and helminth infections in adults in Lao PDR. In fact, this is the first time the association of O. viverrini infection with DM was investigated. Third, we used an internationally certified HbAlc test, which was able to capture most of the previously diagnosed DM cases. The HbA1c point-of-care method applied was validated for use in hot and remote low-income settings in the context of our previous study in South Africa [37]. The validity of our HbA1c findings is further supported by their positive association with validated DM risk factors such as age, BMI and smoking. Finally, to achieve a satisfactory sensitivity for the helminth diagnosis, we examined two stool samples per person, which is known to increase the sensitivity [40].

There are however, some limitations in our study. It is known that $T$. solium, $T$. saginata and $T$. asiatica are endemic in Asia [41]. In our study, we did not distinguish the Taenia species, and hence could not study the species specific associations with $\mathrm{HbAlc}$ in the blood. Moreover, due to the cross-sectional nature of our study, we were not able to identify the time-course relationship between infections and DM development. Reverse causation is a concern as DM patients have an increased susceptibility to infections due to their immune dysfunction [42]. The observed association between Taenia spp. and HbA1c could therefore be real, a chance finding, explained by confounding or due to reverse causation. Finally, we could not rule out other associated infectious or non-infectious conditions of study participants, which might influence the blood glucose levels and confound, modify or mediate the observed infection-DM associations. Multi-parasitism 
is very common in different provinces in Lao PDR and a significant association has been observed between $S$. mekongi and hookworm in Southern Lao PDR [23], as well as between $S$. mansoni and hookworm in Côte d'Ivoire [43]. Since each parasite has a different effect on blood sugar, energy balance, and immunity, co-infections status may play an important role in studying dual disease burden.

\section{Conclusions}

Our study found an alarmingly high level of uncontrolled hyperglycaemia in both, urban and rural Lao PDR. These results are not consistent, with a strong role of common infections, such as $O$. viverrini, explaining the high diabetes burden observed. Larger and longitudinal studies including biomarkers and liver ultrasounds are warranted to further study the causes of DM in Lao PDR. The Lao PDR health system must work on strengthening its healthcare services in the domain of DM screening and treatment.

\section{Additional files}

\section{Additional file 1: Multilingual abstract in the five official working} languages of the United Nations. (PDF $272 \mathrm{~kb}$ )

Additional file 2: Independent association of single infections and infection groups with $\mathrm{HbA} 1 \mathrm{c}$ in participants with $\mathrm{HbA} 1 \mathrm{c}$ levels in the normal range (columns to the left) $(N=609)$ and in the normal and prediabetic range (columns to the right) $(N=1179)$, excluding participants self-reporting a physician-diagnosis of DM. (PDF $80 \mathrm{~kb}$ )

Additional file 3: Independent association of single infections with preDM and DM status combined and compared to non-DM, with and without adjustment for BMI and physical inactivity, excluding participants selfreporting a physician diagnosis of DM and intake of DM medication $\left(N=1466^{1}\right)$ (PDF $\left.80 \mathrm{~kb}\right)$

\section{Abbreviations}

BMI: Body mass index; Cl: Confidence interval; DM: Diabetes mellitus; FECT: Formalin-ether concentration technique; ID: Infectious diseases; IFMT: The Francophone Institute for Tropical Medicine; Lao PDR: Lao People's Democratic Republic; LMICs: Low- and middle income countries; NCDs: Noncommunicable diseases; OR: Odd ratio; SD: Standard deviation; STH: Soiltransmitted helminths; WHO: World Health Organization

\section{Acknowledgements}

We sincerely thank the population of the study villages and the authorities at the village, district and provincial departments for their active participation and their interest in the study.

\section{Funding}

We are grateful to the financial support of the Agence Universitaire de la Francophonie and the Rudolf Geigy Foundation, Basel, Switzerland.

\section{Availability of data and materials}

The data from this study are available on request from corresponding author.

\section{Authors' contributions}

NSNH, PO, PP, DR and NPH designed the study. PP, SS, MV, VPN, XDT, PSY, $\mathrm{NAH}, \mathrm{NDS}, \mathrm{AH}, \mathrm{BS}, \mathrm{DX}, \mathrm{DRR}, \mathrm{PB}, \mathrm{PPP}, \mathrm{SDS}, \mathrm{YXL}, \mathrm{KT}$, XSX, PTV developed the study protocol, performed the field work and contributed to the data analysis. BS conducted the stool analysis. NSNH, PO, PP, DR and NPH performed the final analysis. NSNH and NPH wrote the first manuscript version. PO, PP, ICE, MI, DR and NPH revised the manuscript. All authors read and approved the final version of the manuscript.

\section{Ethics approval and consent to participate}

The National Ethics Committee for Health Research (NECHR) of the Ministry of Health (MoH) of Lao PDR (approval No. 017 NIOPH/NECHR, 14 March 2016) approved the study protocol. After research aim, methods, risks and benefits of the study were explained in detail to participants, district and provincial health authorities, written informed consent was also obtained from each participant prior data collection. Diagnosed helminth infection was treated according to the national treatment guidelines.

\section{Consent for publication}

Not Applicable.

\section{Competing interests}

The authors declare that they have no competing interest.

\section{Author details}

${ }^{1}$ Department of Epidemiology and Public Health, Swiss Tropical and Public Health Institute, PO Box, 4002, 4051 Basel, Switzerland. ${ }^{2}$ University of Basel, Basel, Switzerland. ${ }^{3}$ The Francophone Institute for Tropical Medicine (International Program for Health in the Tropics), Vientiane, Lao PDR. ${ }^{4}$ Lao Tropical and Public Health Institute, Ministry of Health, Vientiane, Lao People's Democratic Republic. ${ }^{5}$ Tropical Disease Research Laboratory, Faculty of Medicine, Khon Kaen University, Khon Kaen, Thailand. 'Université Laval, Quebec City, Canada.

Received: 18 May 2018 Accepted: 2 October 2018

Published online: 06 November 2018

\section{References}

1. IDF. International Diabetes Foundation. Diabetes Atlas - 8th edition. http:// diabetesatlas.org/resources/2017-atlas.html. Accessed 25 Feb 2018.

2. WHO World Health Organization. Soil-transmitted helminth infections. http://www.who.int/news-room/fact-sheets/detail/soil-transmitted-helminthinfections. Accessed 21 Nov 2017.

3. Soukhathammavong PA, Sayasone S, Phongluxa K, Xayaseng V, Utzinger J, Vounatsou $P$, et al. Low efficacy of single-dose albendazole and mebendazole against hookworm and effect on concomitant helminth infection in Lao PDR. PLoS Negl Trop Dis. 2012;6(1):e1417.

4. Vonghachack Y, Odermatt P, Taisayyavong K, Phounsavath S, Akkhavong K, Sayasone S. Transmission of Opisthorchis viverrini, Schistosoma mekongi and soil-transmitted helminthes on the Mekong Islands Southern Lao PDR. Infect Dis Poverty. 2017:6(1):131.

5. Forrer A, Vounatsou P, Sayasone S, Vonghachack Y, Bouakhasith D, Utzinger J, et al. Risk profiling of hookworm infection and intensity in Southern Lao People's Democratic Republic using bayesian models. PLoS Negl Trop Dis. 2015;9(3):e0003486.

6. Vonghachack Y, Sayasone S, Bouakhasith D, Taisayavong K, Akkavong K, Odermatt P. Epidemiology of Strongyloides stercoralis on Mekong islands in southern Laos. Acta Trop. 2015;141:289-94.

7. Forrer A, Sayasone S, Vounatsou P, Vonghachack Y, Bouakhasith D, Vogt S, et al. Spatial distribution of, and risk factors for, Opisthorchis viverrini infection in Southern Lao PDR. PLoS Negl Trop Dis. 2012;6(2):e1481.

8. Sayasone S, Odermatt P, Phoumindr N, Vongsaravane $X$, Sensombath V, Phetsouvanh $\mathrm{R}$, et al. Epidemiology of Opisthorchis viverrini in a rural district of southern Lao PDR. Trans R Soc Trop Med Hyg. 2007;101(1):40-7.

9. WHO World Health Organization. Lao People's Democratic Republic Country Profile. http://www.who.int/diabetes/country-profiles/lao_en.pdf?ua=1. Accesssed 14 Jan 2018.

10. Aravindhan V, Anand G. Cell type-specific immunomodulation induced by helminthes: effect on metainflammation, insulin resistance and type-2 diabetes. Am J Trop Med Hyg. 2017;97(6):1650-61.

11. Lorenzo C, Wagenknecht LE, Hanley AJ, Rewers MJ, Karter AJ, Haffner SM. A1C between 5.7 and $6.4 \%$ as a marker for identifying pre-diabetes, insulin sensitivity and secretion, and cardiovascular risk factors: the Insulin Resistance Atherosclerosis Study (IRAS). Diabetes Care. 2010;33(9):2104-9.

12. Vyas S, Kumaranayake L. Constructing socio-economic status indices: how to use principal components analysis. Health Policy Plan. 2006;21(6):459-68. 
13. Ahmad N, Adam SI, Nawi AM, Hassan MR, Ghazi HF. Abdominal obesity indicators: waist circumference or waist-to-hip ratio in Malaysian adults population. Int J Prev Med. 2016;7:82.

14. Zhang YH, Ma WJ, Thomas GN, Xu YJ, Lao XQ, Xu XJ, et al. Diabetes and prediabetes as determined by glycated haemoglobin A1c and glucose levels in a developing southern Chinese population. PLoS One. 2012;7(5):e37260.

15. Boillat-Blanco N, Bovet $P$, Ramaiya KL, Mganga M, Minja LT, Saleh L, et al. Association between tuberculosis, diabetes and 25 hydroxyvitamin $D$ in Tanzania: a longitudinal case control study. BMC Infect Dis. 2016;16(1):626.

16. Misra A, Khurana L. Obesity-related non-communicable diseases: South Asians vs White Caucasians. Int J Obes. 2010;35(2):167-87.

17. Rim HJ, Chai JY, Min DY, Cho SY, Eom KS, Hong SJ, et al. Prevalence of intestinal parasite infections on a national scale among primary schoolchildren in Laos. Parasitol Res. 2003;91(4):267-72.

18. Ohta N, Waikagul J. Disease burden and epidemiology of soil-transmitted helminthiases and schistosomiasis in Asia: the Japanese perspective. Trends Parasitol. 2007;23(1):30-5.

19. Sayasone S, Vonghajack Y, Vanmany M, Rasphone O, Tesana S, Utzinger J, et al. Diversity of human intestinal helminthiasis in Lao PDR. Trans R Soc Trop Med Hyg. 2009;103(3):247-54.

20. Sayasone S, Utzinger J, Akkhavong K, Odermatt P. Multiparasitism and intensity of helminth infections in relation to symptoms and nutritional status among children: a cross-sectional study in southern Lao People's Democratic Republic. Acta Trop. 2015;141:322-31.

21. Sayasone S, Rasphone $O$, Vanmany M, Vounatsou P, Utzinger J, Tanner M, et al. Severe morbidity due to Opisthorchis viverrini and Schistosoma mekongi infection in Lao People's Democratic Republic. Clin Infect Dis. 2012:55:54-7.

22. Sripa B, Kaewkes S, Intapan PM, Maleewong W, Brindley PJ. Food-borne trematodiases in Southeast Asia epidemiology, pathology, clinical manifestation and control. Adv Parasitol. 2010;72:305-50.

23. Sayasone S, Mak TK, Vanmany M, Rasphone O, Vounatsou P, Utzinger J, et al. Helminth and intestinal protozoa infections, multiparasitism and risk factors in Champasack Province, Lao People's Democratic Republic. PLoS Negl Trop Dis. 2011;5(4):e1037.

24. Ayé Soukhathammavong $P$, Rajpho $V$, Phongluxa $K$, Vonghachack $Y$, Hattendorf J, Hongvanthong B, et al. Subtle to severe hepatobiliary morbidity in Opisthorchis viverrini endemic settings in southern Laos. Acta Trop. 2015;141:303-9.

25. Andrews RH, Sithithaworn P, Petney TN. Opisthorchis viverrini: an underestimated parasite in world health. Trends Parasitol. 2008;24(11):497-501.

26. Sripa B, Bethony JM, Sithithaworn P, Kaewkes S, Mairiang E, Loukas A, et al. Opisthorchiasis and Opisthorchis-associated cholangiocarcinoma in Thailand and Laos. Acta Trop. 2011;120(Suppl 1):S158-68.

27. Jung $\mathrm{CH}$, Lee WJ, Hwang JY, Yu JH, Shin MS, Lee MJ, et al. Assessment of the fatty liver index as an indicator of hepatic steatosis for predicting incident diabetes independently of insulin resistance in a Korean population. Diabet Med. 2013;30(4):428-35.

28. Lambeth SM, Carson T, Lowe J, Ramaraj T, Leff JW, Luo L, et al. Composition, diversity and abundance of gut microbiome in prediabetes and type 2 diabetes. J Diabetes Obes. 2015;2(3):1-7.

29. Chng KR, Chan SH, Ng AHQ, Li C, Jusakul A, Bertrand D, et al. Tissue microbiome profiling identifies an enrichment of specific enteric bacteria in Opisthorchis viverrini associated cholangiocarcinoma. EBioMedicine. 2016;8:195-202.

30. de Aluja AS, Suarez-Marin R, Sciutto-Conde E, Morales-Soto J, Martinez-Maya $\mathrm{J}$, Villalobos N. Evaluation of the impact of a control program against taeniasis-cysticercosis (Taenia solium). Salud Publica Mex 2014;56(3):259-265. (in Spanish).

31. Fleury A, Trejo A, Cisneros H, García-Navarrete R, Villalobos N, Hernández M, et al. Taenia solium: Development of an Experimental Model of Porcine Neurocysticercosis. PLoS Negl Trop Dis. 2015;9(8):e0003980.

32. Tahapary DL, de Ruiter K, Martin I, van Lieshout L, Guigas B, Soewondo P, et al. Helminth infections and type 2 diabetes: a cluster-randomized placebo controlled SUGARSPIN trial in Nangapanda, Flores, Indonesia. BMC Infect Dis. 2015;15:133.

33. Wiria AE, Wammes LJ, Hamid F, Dekkers OM, Prasetyani MA, May L, et al. Relationship between carotid intima media thickness and helminth infections on Flores Island, Indonesia. PLoS One. 2013;8(1):e54855.

34. Aravindhan V, Mohan V, Surendar J, Muralidhara Rao M, Pavankumar N, Deepa $M$, et al. Decreased prevalence of lymphatic filariasis among diabetic subjects associated with a diminished pro-inflammatory cytokine response (CURES 83). PLoS Negl Trop Dis. 2010;4(6):e707.
35. Chen Y, Lu J, Huang Y, Wang T, Xu Y, Xu M, et al. Association of Previous Schistosome Infection With Diabetes and Metabolic Syndrome: A CrossSectional Study in Rural China. J Clin Endocrinol Metab. 2012;98(2):E283-7.

36. Mendonça SCL, MdRF G-P, Rodrigues RM, Ferreira Á Jr, Costa-Cruz JM. Is there an association between positive Strongyloides stercoralis serology and diabetes mellitus? Acta Trop. 2006;99(1):102-5.

37. Htun NSN, Odermatt P, Muller I, Yap P, Steinmann P, Schindler C, et al. Association between gastrointestinal tract infections and glycated hemoglobin in school children of poor neighborhoods in Port Elizabeth. South Africa PLoS Negl Trop Dis. 2018;12(3):e0006332.

38. Steinmann P, Zhou XN, Li YL, Li HJ, Chen SR, Yang Z, et al. Helminth infections and risk factor analysis among residents in Eryuan county, Yunnan province, China. Acta Trop. 2007;104(1):38-51.

39. Tahapary DL, de Ruiter K, Martin I, Brienen EAT, van Lieshout L, Cobbaert CM, et al. Effect of anthelmintic treatment on insulin resistance: a cluster-randomized placebo-controlled trial in Indonesia. Clin Infect Dis. 2017;65(5):764-71.

40. Sayasone S, Utzinger J, Akkhavong K, Odermatt P. Repeated stool sampling and use of multiple techniques enhance the sensitivity of helminth diagnosis: a cross-sectional survey in southern Lao People's Democratic Republic. Acta Trop. 2015;141:315-21.

41. Ito A, Nakao M, Wandra T. Human taeniasis and cysticercosis in Asia. Lancet. 2003;362(9399):1918-20.

42. Muller LM, Gorter K, Hak E, Goudzwaard WL, Schellevis FG, Hoepelman Al, et al. Increased risk of common infections in patients with type 1 and type 2 diabetes mellitus. Clin Infect Dis. 2005;41(3):281-8.

43. Matthys B, Tschannen AB, Tian-Bi NT, Comoe H, Diabate S, Traore M, et al. Risk factors for Schistosoma mansoni and hookworm in urban farming communities in western Cote d'Ivoire. Tropical Med Int Health. 2007;12(6):709-23.
Ready to submit your research? Choose BMC and benefit from:

- fast, convenient online submission

- thorough peer review by experienced researchers in your field

- rapid publication on acceptance

- support for research data, including large and complex data types

- gold Open Access which fosters wider collaboration and increased citations

- maximum visibility for your research: over $100 \mathrm{M}$ website views per year

At BMC, research is always in progress.

Learn more biomedcentral.com/submissions 